\title{
Illocutionary Force and Translation: A Case Study of Chinese Renditions of The Merry Wives of Windsor*
}

\author{
GUAN Xing-zhong \\ Beijing Language and Culture University, Beijing, China
}

\begin{abstract}
This research seeks to contribute to translation studies by examining the illocutionary force of the speech act theory. It identifies two senses of illocutionary force: The active function of language is defined as $\mathrm{IF}_{1}$ and the varying degrees of the strength of the speech act are defined as $\mathrm{IF}_{2}$. The implications of the two senses of illocutionary force for translation studies are discussed in a case study of the translation of directives in Chinese versions of Shakespeare's play, The Merry Wives of Windsor. Translation shifts in transferring $\mathrm{IF}_{2}$, as manifested in pragmatic duality features of directness/ indirectness, tone articles, repetition of verbs, action measure verbs, upgrader “给我” and honorific addressing terms and vocatives are discussed. The notion's potential as a criterion to evaluate translation quality is also explored.
\end{abstract}

Keywords: illocutionary force, speech act theory, directives, Chinese versions of The Merry Wives of Windsor, Shakespeare

\section{Introduction}

The speech act theory of pragmatics studies "the unit of linguistic communication" in everyday life (Searle, 1969/2001, p. 16). Wierzbicka (1987, iii) even conceives of public life as a "gigantic network of speech acts", consisting of threats, condemnations, offers, demands, negotiations, agreements, and so on. Given that this established theory of "important vehicles of life" (Aikhenvald, 2010, p. 2) has influenced many interdisciplinary fields, it is a little surprising that few attempts have been made to understand its applications in translation practices, particularly in the translations of dramas and fictions in which abundant examples of speech acts can be found. ${ }^{1}$ This article explores the significance of "illocutionary force", which is a key term of speech act theory for translation studies. It is hoped that this article will fill, to some extent, bridge the research gap of the speech act theory application in translation practices.

The article is structured as follows: First, a brief and critical overview of previous research about

\footnotetext{
* Acknowledgements:This work was supported by the Ministry of Education, China under the grant of Research Fund for Young Scholars of Social Science (教育部人文社会科学研究青年基金 No. 11YJC 740030 “基于语料库英汉指令言语行为对比与语 力翻译研究”).

GUAN Xing-zhong, associate professor, Ph.D., School of Translation and Interpreting, Beijing Language and Culture University.

${ }^{1}$ Austin excludes performative utterances on stage from consideration because these speech acts are "hollow", "void", and "parasitic" in nature (1962/2002, p. 22). This narrow perspective has been continually challenged in the past decades. See, e.g., Pratt (1977, p. 86) and Petrey (1990, pp. 86-95).
} 
illocutionary force is given in section two. The two senses of illocutionary force, the active functions of language as $\mathrm{IF}_{1}$ and the varying degrees of a speech act's strength as $\mathrm{IF}_{2}$, are also identified. Next, section three discusses these forces' theoretical implications for translation studies. Section four then presents a case study of the "translation shifts" of $\mathrm{IF}_{2}$ with examples from Chinese renditions of directives in Shakespeare's play The Merry Wives of Windsor, ${ }^{2}$ followed by a discussion of the factors leading to these departures from formal correspondence in the process of translation. Finally, its significance for translation studies is summarized in the conclusion.

\section{Illocutionary Force as a Notion}

The term "illocutionary force" can be traced back to Frege's On Sense and Reference, published in 1892, in which he makes a distinction between sense and force. However, because force has no bearing on "objective truth", it is never his main focus. Scholars' familiarity with the term is attributed more to Austin's influential study in How to Do Things with Words (1962/2002). Austin explores the usage of words from the perspective that words perform an action in conversation and he defines illocutionary forces as "different types of function of language" (Austin, 1962/2002, pp. 98-99).

Echoing Searle (1979/2001) who attempts to synthesize ideas about speech act theory, Vanderveken (1990) postulates that "there are only five primitive illocutionary forces: assertives, directives, commissives, expressives, and declaratives" (p. 125). Such a blanket claim of illocutionary force, however, is confusing, for the metaphor of "force" itself indicates that it can occupy any position on a single continuum of a force vector. The taxonomy overlooks the fact that, even within a speech act, illocutionary force can be strengthened or mitigated. In this sense, though it is acceptable to claim the five basic functions of a language, it is rather misleading to say that there are only five forces. Takahashi (2004) contends that the force of an imperative utterance "can best be analyzed in terms of degree, as opposed to [the traditional] all-or-nothing conception" (p. 29). Similar views include Talmy's (1988), Sweetser's (1990/2002) and Sbisà (2001), which cognitively note the similarity between socio-physical force and the concept of force in a speech act. In his later works, Takahashi (2012) provides formula for analysis of the degrees of imperative force in actual context in terms of numerical values. Since scholars use the same term for two notions of quite different nature, to avoid confusion, the traditional use of illocutionary force is referred to as $\mathrm{IF}_{1}$ hereinafter in this article and the extended sense of illocutionary force is termed as $\mathrm{IF}_{2}$ for the sake of convenience of discussion.

Differences between $\mathrm{IF}_{1}$ and $\mathrm{IF}_{2}$ are more clearly shown in the continuum Givón created (2005, p. 172), which spans from the most direct speech acts directives, to the least direct one, hints (a conventional indirect speech act):

\section{Group one}

Prototypical imperative

(a) Pass the salt.

(b) Please pass the salt.

(c) Pass the salt, would you please?

\footnotetext{
${ }^{2}$ The English version for the play is The Norton Shakespeare International Student Edition (Greenblatt, 1986/1997) based on the Oxford Shakespeare.
} 
(d) Would you please pass the salt?

(e) Could you please pass the salt?

(f) Can you see the salt?

(g) Do you see the salt?

(h) Is there any salt around?

(i) Was there any salt there?

Prototypical interrogative

In appropriate contexts, the $\mathrm{IF}_{1}$ of utterances in Group one can all be considered as directive speech acts to pass the salt. However, the $\mathrm{IF}_{2}$ involved are delivered quite differently. As (a) manifests, directives can be syntactically realized through the straightforward coding of canonic imperatives, which are more imposing. Yet, they can also be expressed via variation of prototypical interrogative and declarative sentences, which are more congruently connected to questions and statements. The latter cases are termed as "indirect speech acts" in speech act theory (Searle, 1979/2001, pp. 31-49) and as "interpersonal metaphor" by Halliday's definition (1994/2000, pp. 342-343). In terms of pragmatic-societal acceptability, such directness/indirectness is a very significant consideration. A directive speech act involves a face-threatening act which results in an inconvenience for the hearer. As a direct speech act of directive, utterance (a) in Group one is rather imposing because it makes the addressee feel "forced" to do something as he has no other options. On the other hand, utterances (c) to (e) can be considered a courteous inquiry about the hearer's willingness/ability to do things, thus such inquiry acts can mask their directive force. Thanks to this "pragmatic duality" feature, these sentences leave a reasonable amount of room for both sides to maneuver in their communication (Blum-Kulka, House, \& Kasper, 1989, p. 45). In case of rejection, the speaker can expediently "deny" that he was actually requesting anything and thus avoids losing face.

In what follows, I shall discuss the theoretical implications of the notion of illocutionary force, in accordance with the two senses, for translation practices.

\section{Theoretical Implications for Translation Studies}

$\mathrm{IF}_{1}$ has shed some new light on translation studies (Hervey, 1998). Hönig and Kussmaul $(1984,80)$ argue that however a sentence is translated, its pragmatic function (the $\mathrm{IF}_{1}$ here) cannot be altered. Similar views can also be found in Hatim and Mason's work (1990). Theoretically, such views help with prescribing how translation can be done. However, the actual picture is more complex in this venture. Transference of $\mathrm{IF}_{1}$ often poses a challenge in cross-cultural translation. Due to linguistic and the restraints of different socio-pragmatic conventions, merely keeping the propositional content in a literal translation may result in a failure to maintain the $\mathrm{IF}_{1}$ of the original text. Consider the difference between greetings in Chinese and Shakespearean English:

(1) [Shallow to Page] Good even and twenty, good Master Page. (MW 2.1.172-173)

晚安, 培琪大令! “ good evening, Master Page”. (ZHU , trans.)

您晚安，佩芝先生。“you have good evening, Master Pag”. (LIANG)

晚安，我的好裴琪大分，二十个下午好。“good evening, good Master page. Twenty good afternoon”. (FANG)

According to the Oxford English Dictionary (2nd ed. [CD-ROM, version 3.0], s.v. "evening"), "Good even and twenty" literally refers to "let God give you twenty good evenings". An issue raised in (1) is that in the new 
cognitive context of Chinese culture, FANG's rendering “二十个下午好 (Twenty good afternoon)” as a greeting may strike Chinese readers as strange. An in-text gloss or footnote may do a sufficient job of clarifying the meaning, though. To ensure its intelligibility, ZHU and LIANG use the common greeting phrases in Chinese instead. Their renditions lose the detail, but keep the overall gist of the $\mathrm{IF}_{1}$ of the original as a greeting. Preserving propositional content is no longer the top consideration for translators.

The preceding discussion is mainly about $\mathrm{IF}_{1}$, which can be taken as the primary, basic aspect of meaning. However, up to now, there have been few discussions about translation studies from the perspective of the extended sense of illocutionary force as $\mathrm{IF}_{2}$. A discrepancy in $\mathrm{IF}_{2}$ in translations may not fundamentally change the utterance's pragmatic function, but it can produce stylistic variations and lead to the loss of the flavour of the original. WANG (1989) maintains that when translating, the translator needs to

follow the original in every aspect, in elegance or vulgarism, in its glibness and decorum, in tone and modality, and in stylistic variation (雅俗如之, 深浅如之, 口气如之, 文体如之). (p. 2)

This indicates that $\mathrm{IF}_{2}$ in the original be fully conveyed in the target language. Yet can such typologically and genetically different languages as Chinese and English achieve such a degree of $\mathrm{IF}_{2}$ equivalency? So far, there have been no systematic empirical translation studies about speech acts of plays. In the coming section, we will examine the translation of speech act of directives in Chinese renditions of The Merry Wives of Windsor, focusing on three research questions: (1) Are there any translation shifts in $\mathrm{IF}_{2}$ transference in the Chinese versions in contrast with the original text? (2) How well is $\mathrm{IF}_{2}$ transferred? (3) What are the possible reasons behind such shifts?

\section{Data and Method of the Case Study}

In this section we will focus on directives because such speech acts "typically embody doing things via saying" (Aikhenvald, 2010, p. 8), thus the present study has a tightly defined scope. The three Chinese versions of the play are by ZHU Sheng-hao 朱生豪 (1948/1978), LIANG Shi-qiu 梁实秋 (1967/2001), and FANG Ping 方平 (2000). The findings are followed by a discussion of the contributing factors leading to translation shifts in $\mathrm{IF}_{2}$.

\section{Syntactic Shifts of Directness/Indirectness in $\mathbf{I F}_{\mathbf{2}}$}

Given the importance of the degree of directness/indirectness in $\mathrm{IF}_{2}$, one would expect that the Chinese renditions would keep the same feature as it is in the English original. Interestingly, though, there are cases of translation shifts from direct imperatives to indirect ones. Next, we will scrutinize this phenomenon more closely with examples.

In the three Chinese versions of the play, a direct speech act is sometimes transformed into an indirect one of declarative, as illustrated from (2) to (3):

(2) [Mistress Page to Ford]

Go get us properties

And tricking for our fairies. (MW4.4.76-77)

我们这些精灵们的一切应用的东西和饰物，也该赶快预备起来了。“properties and tricking for our fairies should be prepared soon". (ZHU, trans.) 
去，给我们拿道具来，还有我们的小仙们的服装。“go fetch properties and clothes for fairies”. (LIANG)

我们那些个小仙子

要用的道具、饰物，你们快去准备吧。“quick to prepare properties and clothes for our fairies”. (FANG)

Example (2) is a direct speech act of demanding in English. "该 (something should be done)" in ZHU's declarative rendition indicates the necessity. It turns the original on-the-record, direct speech act into an off-the-record, indirect speech act. However, in this scene, Mistress Page need not talk in a camouflaged manner because her proposal to dupe Falstaff is fully justified. Moreover, the audience members are her friends and acquaintances and therefore, there is no need for such extravagant courtesy. The interpersonal relationship is not right in ZHU's rendition.

Analogously, the $\mathrm{IF}_{2}$ of performatives can have a metaphorical alternation into interrogatives. Consider example (3):

(3) [Ford to all] I beseech you, follow. See but the issue of my jealousy. (MW 4.2.170-171)

列位，请你们跟我来好不好? 看看我究竟是不是瞎起疑心。“isn't it a good idea for you gentlemen to follow me?...” (ZHU , trans.)

我请你们，跟我去：只是去看看我的猜疑的结果。“I am asking you to follow me...” (LIANG)

我这里请求大家跟我来吧; 看看我吃醋吃的究竟有没有名堂吧。“Here I am requesting you all follow me.”... (FANG)

The original sentence is a directive of requesting. ZHU's interrogative with a question mark and the expression “好不好” adds an extra layer of $\mathrm{IF}_{1}$, making it an inquiry and giving more concessions to the addressees. This duality feature of an indirect speech act undesirably changes the strength of $\mathrm{IF}_{2}$ from the original.

As we proceed, a question can be raised at this time: why there are such metaphorical shifts in the target language? Our working assumption of the reason for this is that it pertains to the idea of negative politeness (Brown \& Levinson, 1987) and translators tend to produce utterances with less coercive force in Chinese. ${ }^{3}$ Subject to discretion of individual translators, they tend to trim and soften the original blunt sentences to "fit" the situation of the dialogue in the play, which creates translation shifts.

\section{Shifts and Unique Features of Chinese Language}

Besides syntactic devices, lexical devices can be indicators for $\mathrm{IF}_{2}$. The Chinese language calls for special lexical devices such as yuqici 语气词 (tone particle), and verb repetition, dongliangci 动量词 (action measure verb construction), which are not found in the English language. Such features may also generate stylistic variations of the $\mathrm{IF}_{2}$ in target text.

Tone particles. Utterance-final tone particles are probably not too surprising in everyday Chinese given that one can practically not produce a spontaneous utterance without attaching a final particle to indicate its pragmatic nuance (Clancy, Thompson, Suzuki, \& Hongyin, 1996). Final particles signaling the speaker's

\footnotetext{
${ }^{3}$ According to Kohnen (2008), the phenomenon of negative politeness was not prominent during Shakespeare's time, there is no need to talk in an indirect way. Chinese translators tend to use more polite indirect speech act in their translations.
} 
attitudes may soften the tone of a question that otherwise might sound presumptuous or inappropriate (LIN, 2005; LI \& Thompson, 1981). Here we use the Tone Particle la 啦 for illustration.

According to the Comprehensive Chinese Dictionary 汉语大词典 (RUAN \& LI), the tone particle 啦 can signal a variety of the speaker's attitudes, such as exclamations of delight, amazement, anger, confirmation, and exhorting. Its application thus provides more expressiveness in $\mathrm{IF}_{2}$. Improper use of 啦 may lead to unintended amusing effects in $\mathrm{IF}_{2}$ transference, as in (4):

(4) [Ford to Master Page and Mistress Page]

Stand not amazed, here is no remedy. (MW5.5.208)

木已成舟，培琪大令，您也不必发呆矓。“the wood has been made into a boat. You cannot change that. Master Page, you can do nothing so do not stand amazed". (ZHU , trans.)

不必惊慌: 这是无可挽回的事：“No panic. This cannot be remedied”. (LIANG)

你们别发愣㕸；生米煮成熟饭㕸。“it is useless standing amazed! [ha! Ha!] for the raw rice is cooked already (you cannot undo it!) [ha! ha!]” (FANG)

Our preliminary reflection is that devoid of tone particles, LIANG's rendering sounds unnatural and unlikely. Master Ford cannot possibly talk in LIANG's pedantic, unconcerned manner to his close friend who is "stunned" by the sad news that his daughter Anne Page has ignored his wishes and secretly eloped with Master Fenton, the penniless man. The bombastic use of two exclamatory 啦s in FANG's translation, by contrast, amusingly gives us a false impression that Master Ford is actually taking pleasure in Master Page's unexpected misfortune.

Verb reiteration. In the Chinese language, verb reiteration can act as a gentle invitation or plea to mitigate the force of an illocutionary act (Ching \& Rimmington, 2004). There are two categories of verb reiteration in the play: AA style, like “瞧瞧” and A一A style, like “燋一瞧”. Both suggest the action concerned will have a short duration. Such connotation reduces the inconvenience to the addressee and thus leads to a decrease of $\mathrm{IF}_{2}$, as shown in (5):

(5) [Falstaff to Mistress Ford] Let me see't, let me see't, O let me see't! (MW3.3.111)

让我看, 让我看, 啊, 让我看! “you must let me look at it”. (ZHU, trans.)

让我看看，让我看看，啊，让我看看! “let me have a look”. (LIANG)

让我㫿焦，让我㫿焦，噢，让我㫿燋吧！“let me have a look.”. (FANG)

Comparing ZHU's single character “看 (kan)” with LIANG's two-letter phrase “看看 (kan kan)” and FANG's “燋燋(qiao qiao)”, we find that ZHU's “看” is more demanding. It seems particularly disconcerting that Knight Falstaff would to talk to a lady in such an indecorous manner. Moreover, repetitions like “看看” and “燋 焦” form a special rhythmic resounding effect in Chinese, which delineates Falstaff's amusing "anxiety”, as he had hoped to have an affair with Mistress Ford but instead is trapped in Ford's house when he comes for his rendezvous with her; Falstaff is frightened out of his wits and more than eager to get out.

Action measure words. Chinese dongliangci 动量词 (action measure words) like “一下 (one time)", and “一点 (a bit)” can be used to understate the difficulties of doing something and it indicates to addressee that he should just have a try (Shao 1996, 101). Such a usage can reduce $\mathrm{IF}_{2}$, as illustrated in (6):

(6) [Mistress Ford to Falstaff] Step into th 'chamber, Sir John. (MW 4.2.8)

爵分, 您进去一下。 “Sir, you go in for a little while”. (ZHU, trans.) 
走进内室里去，约翰爵士。“go into the chamber, Sir John”. (LIANG)

到内室里去躲一下, 约翰老令。“go in [the] chamber for a while to hide, Sir John”. (FANG)

LIANG's rendition without the action measure words sounds rather demanding. It is hard to imagine that a lady like Mistress Ford can speak so rudely to a knight. By contrast, thanks to the action measure expression "下 (for a little while)", the $\mathrm{IF}_{2}$ in ZHU's and FANG's renderings is much eased and more acceptable.

Upgrader “给我” for emphasis. In Chinese, the presence of the upgrader phrase “给我 (for me)” can give emphasis to the authority of the speaker and it can serve to boost the $\mathrm{IF}_{2}$ :

(7) [Ford to his imagined foe] Come forth, sirrah! (MW 4.2.117)

过来, 狗才! “come forth, sirrah”. (ZHU, trans.)

出来吧, 伙计! “come out, you”. (LIANG)

喂, 给我滚出来吧! “hi, come out for me”. (FANG)

Evidently, $\mathrm{IF}_{2}$ in FANG's rendition is much reinforced with “给我”.

\section{请您 in requesting}

Politeness marker “请” can render the sentence more polite in a request, thus reducing the strength of the $\mathrm{IF}_{2}$. Its occurrence with the honorific pronoun nin 您 to address someone with higher status further mitigates the $\mathrm{IF}_{2}$ involved (Ching \& Rimmington, 1997/2006). Compare (8):

(8) [Anne Page to Master Slender] I pray you, sir, walk in. (MW 1.1.196)

世兄，请您进去吧。“sir, you walk in please” (ZHU , trans.)

先生，我请您走进去吧。“sir, I invite you to walk in please” (LIANG)

我求你啦，少分，往里面走吧。“I am begging you, Sir, do walk in” (FANG)

In this scene, Anne Page invites Master Slender inside her father's house for a meal. She fully displays her womanly virtue of patience and courtesy here. “请您” in ZHU's and LIANG's renditions are appropriate for the situational context. FANG's “我求你啦” (I am begging you), however, with an emphasis on the strength of the request, loses the tinge of the original and makes us think that Anne is annoyed by Slender's reluctance to go in.

Position adjustment for vocatives. Addressing terms symbolize the psychological distance between interlocutors. It is noteworthy that vocatives are normally put at the front part of the utterance in the Chinese language while in English vocatives enjoy more freedom in terms of their positions (Leech, 1999; Busse, 2006). ZHU frequently adjusts vocative positions to the front, which makes it more natural in Chinese. Consider (9):

(9) [Mistress Ford to servants] Go, sirs, take the basket again on your shoulders. (MW4.2. 92)

你们再把那管子抬出去；“you again take the basket out” (ZHU , trans.)

去吧，你们，再把筐抬起来; “go, you, take the basket again on your shoulders” (LIANG)

快些儿, 劳驾两位，再把那管衣裳扛着往外走。“hurry, you two, take the basket out again on your shoulders" (FANG)

Here, LIANG's and FANG's renditions break the rhythm of the Chinese language and create a awkward, stilted effect in $\mathrm{IF}_{2}$ transference.

\section{Statistics and Discussions}

In this section, the occurrences of abovementioned translation shifts are provided in Table 1, followed by an analysis of the factors leading to such translation shifts. 
Table 1

Statistics of Translation Shifts in Chinese Versions of The Merry Wives of Windsor

\begin{tabular}{llllllll}
\hline \multirow{2}{*}{ Translator } & In/directness & $\begin{array}{l}\text { Tone Particle } \\
\text { 啦 吧 }\end{array}$ & $\begin{array}{l}\text { Verb } \\
\text { Repetition }\end{array}$ & $\begin{array}{l}\text { Action Measure } \\
\text { Word }\end{array}$ & Upgrader 给我 & $\begin{array}{l}\text { Politeness Marker } \\
\text { 请您 }\end{array}$ & $\begin{array}{l}\text { Vocative Position } \\
\text { Adjustments }\end{array}$ \\
\hline ZHU & 13 & 15 & 26 & 11 & 12 & 12 & 27 \\
LIANG & 4 & 9 & 11 & 8 & 6 & 1 & 3 \\
FANG & 8 & 61 & 21 & 6 & 22 & 0 & 6 \\
\hline
\end{tabular}

It can be observed that overall ZHU's translation is the most "manipulative". Among the three, he has most translation shifts. By contrast, LIANG's version is the most rigid one. He has remarkable underuse of linguistic features peculiar to the Chinese language, such as tone particles, verb repetitions, and vocatives adjustments, makes his language dry, monotonous and unexpressive, as shown in examples of (4), (6), and (9). FANG's version is somehow in between. His translation has manifested a plethora of usage of the tone particles, and this makes his language unnecessarily "juicy" in conveying $\mathrm{IF}_{2}$. He also employs verb repetition and has most upgrader “给我”, but has fewer modifications of vocatives positions and syntactic directness/indirectness.

The translators' choices can be attributed to the translator's purpose of his translation and the consequent translation approach adopted by them. In the preface to his translation, ZHU (2012) spells out that his aim is to "popularize Shakespeare plays among common Chinese readers" (p. 1). For him, readability is a crucial consideration. To achieve such a purpose, it is allowable to improve, to embellish and even to reshuffle the utterances:

The guiding principle for my translation is, above all, to keep the shenyun 神韵 (spirit and verve) of the original. If such a requirement cannot be satisfactorily met, the next option is to clearly render the meaning and faithfully convey the yixu 意趣 (charm) of the original. I do not see a word-for-word translation as a good translation choice. If the original does not fit into [the] syntax of [the] Chinese language, I will brood over the issue many times and even reshuffle the structures of the original to ensure the author's meaning is manifested clearly instead of letting it be obscured by award wordings. (ZHU, 1948/1978, p. 1)

ZHU's reader-oriented translation approach helps to explain why ZHU's renditions have frequent occurrences of translation shifts.

LIANG (1981) has a different view about his translation purpose. According to LIANG, his endeavor is to “arouse readers' interest in the original" (pp. 18-19). Unlike ZHU, LIANG's approach is original text-oriented and he even considers punctuations of the original may have "special meaning", hence should be "scrupulously reiterated" (LIANG, 2002, pp. 537-538). It is no surprising to find that he has negligible four cases of syntactic adjustments in directness/indirectness and he himself seems not bothered too much with adjustments of the positions of vocatives, occurrences of which are also exceptionally low in contrast with that of ZHU's and FANG's. He sporadically used tone particles㕸, 吧. The use of repetition of verbs, action measure words and modifications of upgrader “给我” and politeness marker “请您” are also to some extent ignored because the original English text does not have such prominent features. What LIANG neglects to note, however, is that the underuse of the special features of the target language may bring about variations in $\mathrm{IF}_{2}$ and makes his renditions sound unnatural, incongruous on more than one occasion, as clearly illustrated in (4), (6), and (9). 
In comparison with ZHU's and LIANG's unambivalent approaches to translation, FANG's rendition is a paradoxical compromise. On the one hand, FANG claims that his rendition is for stage performance and he invites his intended “ear readers" 听觉型读者 to "imagine themselves to be personally present at the scene described through the tone of language and vivid depiction (有声有色，犹如身临其境)” (FANG, 2001, p. 66). Such an overemphasis explains why he employs exceedingly large number of tone particles in his translations, which can make his renderings of $\mathrm{IF}_{2}$ more colloquial and more expressive for performance purpose. Out of similar consideration of performability, FANG also has the top number of occurrences in upgrader “给我” to boost $\mathrm{IF}_{2}$ and he has 21 cases of verb repetition to mitigate $\mathrm{F}_{2}$. On the other hand, FANG also holds that "sentence order [and] syntactic construction should not be altered which otherwise may bring damage to the original tone". FANG prefers to minimize "distortions" 失真 and keep "the full flavor of the original" by closely following the syntax of the original (FANG, 2001, pp. 68-69). This restrains his further flexibility for transferring $\mathrm{IF}_{2}$ in his translation.

\section{Conclusion}

The findings in the three Chinese translations of Shakespeare play Merry Wives of Windsor suggest the notion of illocutionary force presupposes translation quality criteria for translation of speech. Sensitive handling of the illocutionary force in the two senses $\mathrm{IF}_{1}$ and $\mathrm{IF}_{2}$ might be an essential aspect of translating skills for translators. $\mathrm{IF}_{1}$ is more fundamental to establish interpersonal relationships and its conveyance in the target text is the basic, minimum requirement for translation of directives. Failure to achieve the $\mathrm{IF}_{1}$ will lead to a complete miscommunication while inadequate handling of the $\mathrm{IF}_{2}$ may result in the partial loss of the flavor of the original utterance. Radical deviations in $\mathrm{IF}_{1}$ and $\mathrm{IF}_{2}$ should be avoided. Overexploitation and under-use of distinctive features of the target language may bring unintended consequences in $\mathrm{IF}_{2}$ transference. Approximation in IF2 may help to achieve spiritual resemblance with the flavour of the source text.

\section{References}

Aikhenvald, A. (2010). Imperatives and commands. Oxford: Oxford University Press.

Austin, L. (1962/2002). How to do things with words. Beijing: Foreign Language Teaching and Research Press.

Blum-Kulka, S., House, J., \& Kasper, G. (1989). Cross-cultural pragmatics: Requests and apologies. Norwood, NJ: Ablex.

Brown, P., \& Levinson, S. (1987). Politeness: Some universals in language use. Cambridge: Cambridge University Press.

Busse, B. (2006). Vocative constructions in the language of Shakespeare. Amsterdam: John Benjamins.

Ching, Y. P., \& Rimmington, D. (2004). Chinese: A comprehensive grammar. London: Routledge.

Ching, Y. P., \& Rimmington, D. (1997/ 2006). Chinese: An essential grammar. London: Routledge.

Clancy, P., Thompson, S., Suzuki, R., \& Hongyin, T. (1996). The conversational use of reactive tokens in English, Japanese, and Mandarin. Journal of Pragmatics, 26, 355-387.

FANG, P. (2001). Xinde renshi he zhuiqiu (New understanding, new pursuit—on translation of new complete Shakspeare plays). Chuban Guangjiao (A Vast View on Publishing), 05, 66-99.

Givón, T. (2005). Context as other minds: The pragmatics of sociality, cognition and communication. Amsterdam: John Benjamins.

Halliday, M. A. K. (1994/2000). An introduction to functional grammar. Beijing: Foreign Language Teaching and Research Press. Hatim, B., \& Mason, I. (1990). Discourse and the translator. London: Longman.

Hervey, S. (1998). Speech acts and illocutionary function in translation methodology. In L. Hickey (Ed.), The pragmatics of translation (pp.10-24). Clevedon: Multilingual Matters.

Hönig, H. G., \& Kussmaul, P. (1984). Strategie der Übersetzung: Einstein Lehr-und Arbeitsbuch (Strategies of translation: Einstein teaching and practice). Tübingen: Gunter Narr. 
HUA, J. G. (2011). Xianqin Yuqici Yanjiu de Ruogan Wenqi (On tone words of early Qin Period). Journal of Ninxia University, 331, 1-7.

Kohnen, T. (2008). Tracing directives through text and time. In A. Jucker \& I. Taavistsainen (Eds.), Speech acts in the history of English (pp. 295-311). Amsterdam: John Benjamins.

Leech, G. (1999). The distribution and function of vocatives in American and British English. In H. Hasselggard \& S. Oksefjell (Ed.), Out of corpora: Studies in honour of Stig Johansson (pp. 107-118). Amsterdam : Rodopi.

LI, C., \& Thompson, S. (1981). Mandarin Chinese: A functional reference grammar. Los Angeles, CA: University of California Press.

LIANG, S. Q. (2002). Liangshiqiu wenji (Anthology of Liang Shiqiu) (Vol. 5). Xiamen: Lujiang Publishing House.

LIANG, S. Q. (1981). Guanyu Shashibiya de fanyi (On Shakespeare's translation). In J. Z. LIU (Ed.), Fanyi lunji (Anthology on translation) (pp. 18-19). Hong Kong: Sanlian publishing House.

LIANG, W. Q. (1988). Chang Xiangsi (Reminiscene). Tabei: Shibao wenhua chubanqiye gongsi.

LIN, H. H. (2005). Contextualizing linguistic politeness in Chinese (Ph.D. dissertation, The Ohio State University).

Petrey, S. (1990). Speech acts and literary theory. New York, NY: Routledge.

Pratt, M. L. (1977). Toward a speech act theory of literary discourse. Bloomington, IN: Indiana University Press.

RUAN, Z. X., \& LI, H. F. (1994/1995). Hanyu dacidian (Comprehensive Chinese grammar). Shanghia: Hanyu Dacidian Chubanshe.

Sbisà, M. (2001). Illocutionary force and degrees of strength in language use. Journal of Pragmatics, 33(12), 1791-1814.

Searle, J. (1969/2001). Speech acts: An essay in the philosophy of language. Beijing: Foreign Language Teaching and Research Press.

Searle, J. (1979/2001). Expression and meaning: Studies in the theory of speech acts. Beijing: Foreign Language Teaching and Research Press.

Shakespeare, W. (1948/1978). Complete Shakespearean plays (Vol. 1). (S. H. ZHU, Trans.). Beijing: People's Literature Publishing House.

Shakespeare, W. (1967/2001). The Merry Wives of Windsor (Vol. 3). (S. Q. LIANG, Trans.). Beijing: China Radio and Television Publishing House.

Shakespeare, W. (2000). Complete Shakespearean plays (Vol. 3). (P. Fang, Trans.). Shijiazhuang: Hebei Provincial Education Press.

SHAO, J. M. (1996). Dongliangci de yuyifenxi jiqi dongcide xuanzeguanxi (Semantic analysis of action measure words). Zhongguo Yuwen, 251(2), 100-109.

Sweetser, E. (1990/2002). From etymology to pragmatics: Metaphorical and cultural aspects of semantic structure. Cambridge: Cambridge University Press.

Takahashi, H. (2004). The English imperative: A cognitive and functional analysis (Ph.D. dissertation, Hokkaido University).

Takahashi, H. (2012). A cognitive linguistic analysis of the English imperative : With special reference to Japanese imperatives. Amsterdam: John benjamins.

Talmy, L. (1988). Force dynamics in language and cognition. Cognitive Science, 12, 49-100.

Vanderveken, D. (1990). Meaning and speech acts: Principles of language use. Cambridge: Cambridge University Press.

WANG, Z. L. (1989). Fanyi: Sikao yu shibi (On translation: Reflections and some translated works). Beijing: Foreign Language Teaching and Research Press.

Wierzbicka, A. (1987). English speech act verbs: A semantic dictionary. Sydney: Academic Press. 